\title{
Stability of Digital Control System for Unmanned Aerial Vehicle with Numerical Analysis
}

\author{
Thanda Win ${ }^{1}$, Hteik Tin Cho Nyunt ${ }^{2}$, Hla Myo Tun ${ }^{3, *}$ \\ ${ }^{1}$ Department of Electronic Engineering, West Yangon Technological University, Yangon Region, Republic of the Union of Myanmar \\ ${ }^{2}$ Department of Electronic Engineering, Government Technical High School (Shwe Pyi Thar), Yangon Region, Republic of the Union of \\ Myanmar \\ ${ }^{3}$ Department of Electronic Engineering, Yangon Technological University, Yangon Region, Republic of the Union of Myanmar
}

\section{Email address:}

ecdepartment.ytu@gmail.com (H. M. Tun)

${ }^{*}$ Corresponding author

\section{To cite this article:}

Thanda Win, Hteik Tin Cho Nyunt, Hla Myo Tun. Stability of Digital Control System for Unmanned Aerial Vehicle with Numerical Analysis. American Journal of Astronomy and Astrophysics. Vol. 8, No. 2, 2020, pp. 15-18. doi: 10.11648/j.ajaa.20200802.11

Received: October 20,2019; Accepted: April 7, 2020; Published: April 17, 2020

\begin{abstract}
The paper presents the analysis on stability of digital control system for unmanned vehicle with numerical analysis. The objective of this study is mainly emphasized on the fulfillment of the advanced control techniques according to the fundamental concepts of digital control system approaches for unmanned aerial vehicle system design. The targeted unmanned aerial vehicle system was designed based on the simple construction under the idea of fixed wing flight system approaches. The stability analyses on unmanned aerial vehicle are vital role to enhance the real world applications. The background concepts on digital control system for stability analysis on dynamic control system like unmanned aerial vehicle system. The appropriate controller design for dynamic control system of unmanned aerial vehicle is vital role to analyze the accurate stability condition for reality. The implementation of numerical analysis on compensator design has been developed by using MATLAB. The physical parameters in these analyses are based on the experimental outcomes from the recent research works in dynamical system implementations. The mathematical approaches are very helpful for numerical analysis on compensator design for the unmanned aerial vehicles schemes. The simulation results confirm that the high performance stability test on unmanned aerial vehicle system has been met with the theoretical works.
\end{abstract}

Keywords: Stability Analysis, Digital Control System, Unmanned Aerial Vehicle, Numerical Analysis, MATLAB

\section{Introduction}

Unmanned aerial vehicles (UAV) are attractive progressively more prevalent as they can be used in a extensive assortment of areas. The technology convoluted is presence uninterruptedly established and its price is persistently diminishing [1]. Whenever open-source developments are presence conceded by research clutches and gradually evidence can be established on the internet, specified by Radio Control devotee societies.

In the UAV field of interest, of the four diverse classifications, it is micro and mini that ensure experimentation a superior development. Although multirotors are the greatest widespread, glider UAVs have supplementary benefits as their self-sufficiency is better. That is why they are applied in area for recognition or to extent additional places that multi-rotors cannot [2].

The fixed wing structural design has been preferred as it is tranquil to preserve than a unadventurous aircraft, and supplementary strong in circumstance of devastating. Customarily the tail agonize the wickedest portion, as the association to the central frame is fragile [3-5].

Concerning mechanism for management, it is thoughtprovoking subsequently, in contradiction of the unadventurous structural design, where there are numerous control surfaces, in a fixed wing UAV we can individual control the flap glance in a symmetric or asymmetric method, dependent which stability is to be organized [6-10].

The research in this study is mainly targeted on the development of appropriate controller or compensator design for fixed wing unmanned aerial vehicle system based on 
digital control techniques. The specific objective is to enhance the stability technique for dynamic control system for unknown body in the floating condition.

The rest of the paper is organized as follows. Section II presents the background concepts on unmanned aerial system. Section III mentions the implementation of research studies. Section IV discusses the results of the analyses. Section $\mathrm{V}$ concludes the results of the studies.

\section{Background Concepts on Fixed Wing UAV and Digital Control}

The background concepts on digital control system are related to pulse transfer function consideration and analysis.

The Fixed-wing Unmanned Aerial Vehicles (FUAVs) have developed significant exceeding the quadrotors in remote sensing applications, fastidiousness agriculture, and reconnaissance. This is because of its aircraft survival, extensive hovering periods, extraordinary speeds and energy proficiency. Owing to the essential non-linearity circumstance of fixed-wing UAVs, nominal control requisite to be realistic to this sort of UAV consequently this is a theme that remnants presence an experiment. In this study we recommend a complete controller design that accomplishes to stabilize the FUAV in a circumstance obligatory to complete assessment and reconnaissance undertakings. Full control is well-defined as it can steady the UAV at several anticipated situation and velocity enchanting the finest angle of attack and aerodynamics [11-12].

\subsection{Concepts of Digital Control System}

A digital control system could be represented by the block diagram shown in Figure 1. In this system, we could specify the exact elements of that control system. The reference input is $\mathrm{r}(\mathrm{t})$ and the controlled variable or output is $\mathrm{C}(\mathrm{t})$. There have been four blocks in this system. The digital controller block, the zero order hold, the plant and the sensor block are very important portion in the digital control system. The combination of digital controller and zero order hold is called the microprocessor of that system. According to the sample periods of $\mathrm{T}$, the error signal e $(\mathrm{t})$ could be made the discrete parameters of error signal $e^{*}(t)$ by using the sampler. After the output of the digital controller, the input signal $\mathrm{u}^{*}(\mathrm{t})$ of zero order hold would be created. And then the output of zero order hold would be $u(t)$ or control input of the plant. The concepts of digital control system are very fashionable for stability analysis of that system.

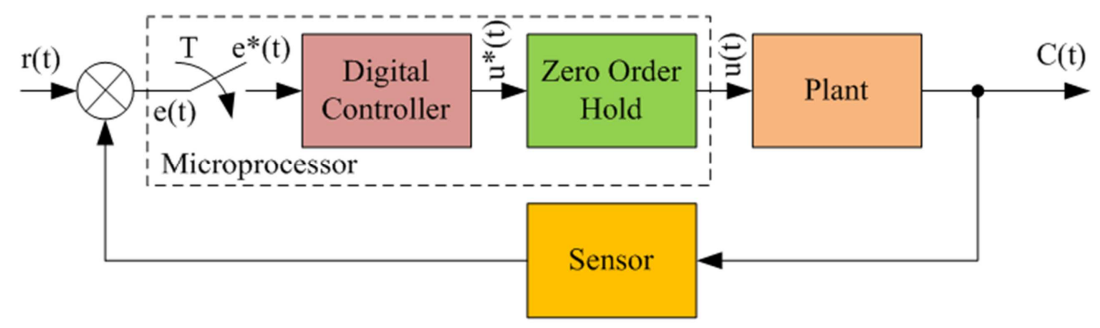

Figure 1. Digital Control System.

\subsection{Concepts of Pulse Transfer Function}

The consideration on error sampled system shown in Figure 2. Since there is no sampler between $G(s)$ and $H(s)$ in the closed-loop system shown in Figure 1, it is a similar arrangement to that shown in [1].

From the closed-loop transfer function concepts, the closed-loop pulse transfer function can be written as

$$
\frac{\mathrm{C}}{\mathrm{R}}(\mathrm{z})=\frac{\mathrm{G}(\mathrm{z})}{1+\mathrm{GH}(\mathrm{z})}
$$

In equation (1)

$$
\mathrm{GH}(\mathrm{z})=\mathrm{Z}\{\mathrm{GH}(\mathrm{s})\}
$$

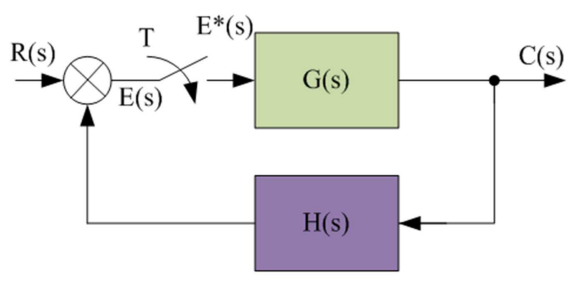

Figure 2. Closed-loop Error Sampled System。
The consideration on the error and the output sampled system is shown in Figure 3. In Figure 3, there is now a sampler between $\mathrm{G}(\mathrm{s})$ and $\mathrm{H}(\mathrm{s})$, which is similar to the open-loop system with sampled system. From the closedloop transfer function equation, the closed-loop pulse transfer function is now written as

$$
\frac{\mathrm{C}}{\mathrm{R}}(\mathrm{z})=\frac{\mathrm{G}(\mathrm{z})}{1+\mathrm{G}(\mathrm{z}) \mathrm{H}(\mathrm{z})}
$$

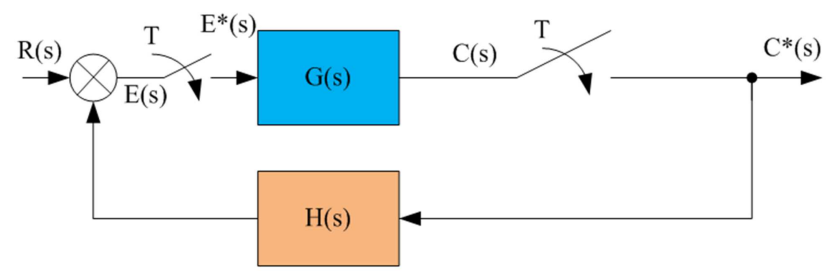

Figure 3. Closed-loop Error and Output Sampled Systems.

\section{Implementation}

Based on the mathematical model of the dynamic control system of unmanned aerial vehicle is expressed in Figure 4. 
When the controller gain $\mathrm{K}$ is unity and the sampling time is 0.5 seconds, we have to consider the open-loop pulse transfer function, the closed-loop pulse transfer function, the difference equation for the discrete time response, the unit step response assuming zero initial conditions and the steady state value of the system output.

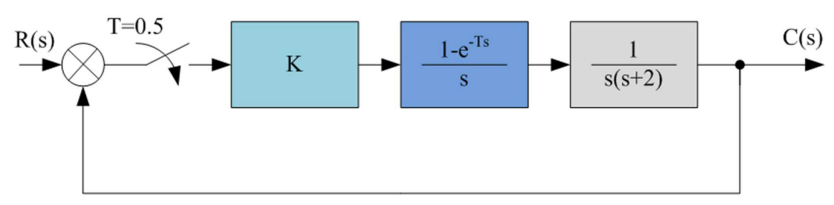

Figure 4. Digital Control System of Unmanned Aerial Vehicle.

According to the physical parameters from the block diagram in Figure 4,

$$
\mathrm{G}(\mathrm{s})=\mathrm{K}\left(\frac{1-\mathrm{e}^{-\mathrm{Ts}}}{\mathrm{s}}\right)\left\{\frac{1}{\mathrm{~s}(\mathrm{~s}+2)}\right\}
$$

Given $\mathrm{K}=1$,

$$
G(s)=\left(1-e^{-T s}\right)\left\{\frac{1}{s^{2}(s+2)}\right\}
$$

Based on the partial fraction expansion,

$$
\frac{1}{\mathrm{~s}^{2}(\mathrm{~s}+2)}=\left\{\frac{\mathrm{A}}{\mathrm{s}}+\frac{\mathrm{B}}{\mathrm{s}^{2}}+\frac{\mathrm{C}}{(\mathrm{s}+2)}\right\}
$$

or

$$
1=s(s+2) A+(s+2) B+s^{2} C
$$

Equating coefficients gives

$$
\begin{gathered}
A=-0.25 \\
B=0.5 \\
C=0.25
\end{gathered}
$$

Substituting these values into equation (5) and (6)

$$
\mathrm{G}(\mathrm{s})=\left(1-\mathrm{e}^{-\mathrm{Ts}}\right)\left\{\frac{-0.25}{\mathrm{~s}}+\frac{0.5}{\mathrm{~s}^{2}}+\frac{0.25}{(\mathrm{~s}+2)}\right\}
$$

or

$$
G(s)=0.25\left(1-e^{-T s}\right)\left\{\frac{-1}{s}+\frac{2}{s^{2}}+\frac{1}{(s+2)}\right\}
$$

Taking z-transforms

$$
G(z)=0.25\left(1-z^{-1}\right)\left\{\frac{-z}{(z-1)}+\frac{2 T z}{(z-1)^{2}}+\frac{z}{\left(z-e^{-2 T}\right)}\right\}
$$

Given $\mathrm{T}=0.5$ second

$$
G(z)=0.25\left(\frac{z-1}{z}\right)\left\{\frac{-1}{(z-1)}+\frac{2 \times 0.5}{(z-1)^{2}}+\frac{z}{(z-0.368)}\right\}
$$

Hence

$$
G(z)=0.25(z-1)\left\{\frac{-1(z-1)(z-0.368)+(z-0.368)+(z-1)^{2}}{(z-1)^{2}(z-0.368)}\right\}
$$

$$
\mathrm{G}(\mathrm{z})=0.25\left\{\frac{-\mathrm{z}^{2}+1.368 \mathrm{z}-0.368+\mathrm{z}-0.368+\mathrm{z}^{2}-2 \mathrm{z}+1}{(\mathrm{z}-1)(\mathrm{z}-0.368)}\right\}
$$

which simplifies to give the open-loop pulse transfer function

$$
G(z)=\left(\frac{0.092 z+0.066}{z^{2}-1.368 z+0.368}\right)
$$

The closed-loop pulse transfer function, from equation (3) is

$$
\frac{C}{R}(z)=\frac{\left(\frac{0.092 z+0.066}{z^{2}-1.368 z+0.368}\right)}{1+\left(\frac{0.092 z+0.066}{z^{2}-1.368 z+0.368}\right)}
$$

which simplifies to give the closed-loop pulse transfer function

$$
\frac{C}{R}(z)=\frac{0.092 z+0.066}{z^{2}-1.276 z+0.434}
$$

or

$$
\frac{\mathrm{C}}{\mathrm{R}}(\mathrm{z})=\frac{0.092 \mathrm{z}^{-1}+0.066 \mathrm{z}^{-2}}{1-1.276 \mathrm{z}^{-1}+0.434 \mathrm{z}^{-2}}
$$

Equation (5) can be expressed as a difference equation

$$
\mathrm{c}(\mathrm{kT})=1.276 \mathrm{c}(\mathrm{k}-1) \mathrm{T}-0.434 \mathrm{c}(\mathrm{k}-2) \mathrm{T}+0.092 \mathrm{r}(\mathrm{k}-1) \mathrm{T}+0.066 \mathrm{r}
$$

$$
(\mathrm{k}-2) \mathrm{T}(32)
$$

Using the difference equation (18), and assuming zero initial conditions, the unit step response would be shown in Figure 5. The response is constructed solely from the knowledge of the two previous sampled outputs and the two previous sampled inputs.

Using the final value problem given in theoretical concepts,

$$
\begin{gathered}
c(\infty)=\lim _{z \rightarrow 1}\left[\left(\frac{z-1}{z}\right) \frac{C}{R}(z) R(z)\right] \\
c(\infty)=\lim _{z \rightarrow 1}\left[\left(\frac{z-1}{z}\right) \frac{0.092 z^{-1}+0.066 z^{-2}}{1-1.276 z^{-1}+0.434 z^{-2}}\left(\frac{z}{z-1}\right)\right] \\
c(\infty)=\frac{0.092+0.066}{1-1.276+0.434}=1.0
\end{gathered}
$$

Hence there is no steady state error.

\section{Results and Discussions}

The simulation results on zero steady state error with the help of numerical analysis. The unit step response is very important to analyze the stability test of digital control system. The target level is 10 arbitrary units for various sampled time from 1 to 4.5 sampled seconds. According to the numerical analysis on stability test and unit step response on the dynamic control system of unmanned aerial vehicle system, the summary of stability test depend only on the steady state error. At present, the control system analysis has been met with zero steady state error of the proposed system. Figure 5 demonstrates the unit step response of unmanned aerial vehicle system. 


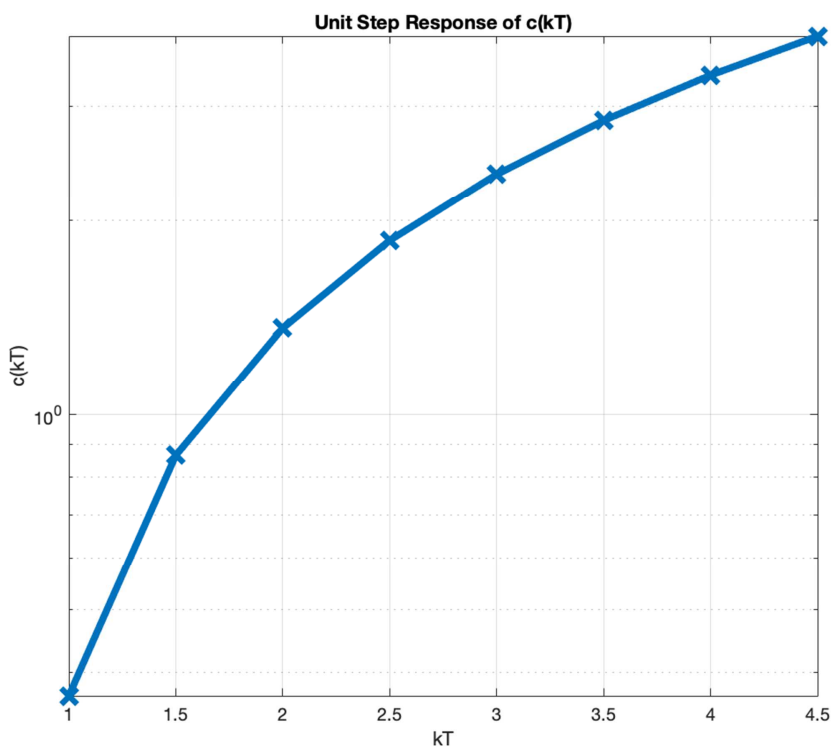

Figure 5. Unit Step Response of Unmanned Aerial Vehicle System.

\section{Conclusion}

The stability test for digital control system is very important for unmanned aerial vehicle system based on numerical analysis. The dynamic control system of unmanned aerial vehicle is developed with appropriate digital controller design. The proposed methodology of compensator design for digital control system of unmanned aerial vehicle is useful for real applications because of the consequence of the analysis. The simulation results for stability analysis are significant impact on dynamic modeling of unmanned aerial vehicle. The numerical analysis on stability test on dynamic control system proves that the high performance stability criteria have been met with the actual control system. This research could solve the unexpected problems for stability test of unmanned aerial vehicle based on the digital control system point of view.

\section{Acknowledgements}

The author would like to thank many colleagues from the Unmanned Aerial System Laboratory of the Department of Electronic Engineering of Yangon Technological University to complete this work.

\section{References}

[1] Mark Edward Peterson. (2006) "The UAV and the current and future regulatory construct for integration into the national airspace system". Journal of Air Law and Commerce, vol. 71 (5) pp. 521-612.

[2] Alexander V. Koldaev. (2007) "Non-military UAV applications".

[3] T. Stastny and R. Siegwart, "Nonlinear model predictive guidance for fixed-wing uavs using identified control augmented dynamics," in 2018 International Conference on Unmanned Aircraft Systems (ICUAS), June 2018, pp. 432442 .

[4] Y. Chen, J. Liang, C. Wang, and Y. Zhang, "Combined of lyapunovstable and active disturbance rejection control for the path following of a small unmanned aerial vehicle," International Journal of Advanced Robotic Systems, vol. 14, no. $2,2017$.

[5] J. Slotine and W. Li, Applied Nonlinear Control. Prentice Hall, 1990.

[6] I. Fantoni, A. Zavala, and R. Lozano, "Global stabilization of a pvtol aircraft with bounded thrust," in Proceedings of the 41st IEEE Conference on Decision and Control, 2002., vol. 4, Dec 2002, pp. 4462-4467 vol. 4.

[7] A. Flores, A. M. de Oca, and G. Flores, "A simple controller for the transition maneuver of a tail-sitter drone," in 2018 IEEE Conference on Decision and Control (CDC), Dec 2018, pp. $4277-4281$.

[8] Burns, R. S. (1997) Intelligent Manufacturing, Journal of Aircraft Engineering and Aerospace Technology, MCB University Press, 69 (5), pp. 440-446.

[9] Cadzow, J. A, and Martens, H. R. (1970) Discrete-Time and Computer Control Systems, Prentice-Hall, Inc., Englewood Cliffs, N. J.

[10] Dorato, P. (ed) (1987) Robust Control, IEEE Press, New York.

[11] Dorf, R. C. (1992) Modern Control Systems, 6th ed., AddisonWesley, Reading, Mass.

[12] Frankin, G. F., Powell, J. D. and Workman, M. L. (1990) Digital Control of Dynamic Systems, 2nd ed., AddisonWesley, Menlow Park, CA. 